\title{
Information and Communication Technologies in Inclusive Education: Selected Practices in Asia
}

\author{
Chau T. M. $\mathrm{Cao}^{1}$ \\ ${ }^{1}$ Graduate School of Asia-Pacific Studies, Waseda University, Tokyo, Japan \\ Correspondence: Chau T. M. Cao, Graduate School of Asia-Pacific Studies, Waseda University, 1 Chome-21-1 \\ Nishiwaseda, Shinjuku City, Tokyo 169-0051, Japan. E-mail: chau@akane.waseda.jp
}

Received: April 23, 2019

Accepted: October 25, 2019 Online Published: November 1, 2019

doi:10.5539/jel.v8n6p159

URL: https://doi.org/10.5539/jel.v8n6p159

\begin{abstract}
Inclusive education has grown from the belief that education is a basic human right, and that it provides the foundation for a more just society. All learners have a right to education, regardless of their individual characteristics or difficulties (UNESCO, 2003). The educational needs of people with disabilities (PWD) are diverse. They need to acquire the fundamental knowledge that enables survival in society under the specific demands caused by functional limitations that hinder participation in ordinary education systems. In this setting, information and communication technologies (ICTs) are indeed a powerful tool to support education and the inclusiveness of the PWD. This paper will review the use of ICTs in education for PWD in an inclusive education setting, with the aim to explore the different possible uses of ICTs in inclusive education for PWD in the Asia region.
\end{abstract}

Keywords: assistive technologies, ICT in education, inclusive education, special education

\section{Introduction}

In the year of 2008, the European Union (EU) realized the importance of information and communication technologies (ICTs) for learning by framing it as "a learner-focused approach to the use of new multimedia technologies and the Internet to improve the quality of learning by facilitating access to resources and services, as well as remote exchanges and collaboration" (European Union, 2008, p. 5). The educational needs of people with disabilities (PWD) are diverse. They need to acquire the fundamental knowledge that enables their survival in society under the specific demands caused by functional limitations that hinder participation in conventional education systems. Therefore, specific special educational needs (SENs) demand accessible technologies that are available constantly for people with handicaps to access education and society (European Agency for Development in Special Needs Education [EADSNE] and UNESCO Institute for Information Technologies in Education [IITE], 2011). As new technology is able to be utilized in-lieu of natural abilities, ICTs-based training becomes more critical every day (UNESCO IITE, 2006).This paper will review the use of ICTs in education for people with disabilities in an inclusive education setting, aiming to reveal and describe the different possibilities of ICT usage in inclusive education for PWD in the Asia region.

\section{Conceptual Framework}

\subsection{People with Disabilities}

The definition of disabilities varies in-between organizations, thus making it quite challenging to get a precise estimation of the number of PWD in the world.

Chamie (1994) defines disability as the universal term for "impairments, activity limitations and participation restrictions, referring to the negative aspects of the interaction between an individual (with a health condition) and that individual's contextual factors (environmental and personal factors)." The World Health Organization (WHO) acknowledges disability as an 'interaction' that cannot be attributed to a person (WHO, 2011). For practical purposes the paper will hereafter use the United Nations (UN)'s definition, due to the larger availability of data using the same definition:

'... [people with disabilities] are those who have long-term physical, mental, intellectual or sensory impairments which in interaction with various barriers may hinder their full and effective participation in society on an equal basis with others' (UN Convention on the Rights of People with Disabilities [CRPD], 
2006, p. 5)

\subsection{Inclusive Education}

Inclusive education (IE) is defined following the concept of UNESCO:

' $\ldots$ an on-going process aimed at offering quality education for all while respecting diversity and the different needs and abilities, characteristics and learning expectations of the students and communities, eliminating all forms of discrimination' (UNESCO_-International Bureau of Education, 2008, p. 3).

\subsection{ICTs Application in IE}

Given the wide range and diversity of education for PWD, this paper cannot cover all possible applications of ICTs in IE. Thus, this paper will employ the framework proposed in the report ICTs in Education for PWD by EADSNE and UNESCO IITE (2013). ICTs used in IE will be divided into four possible areas of application:

(i) Supporting personal access to information and knowledge: ICT as a tool to improve a learner's access to information and knowledge in formal and non-formal learning situations.

(ii) Supporting learning and teaching situations: ICT for pedagogical, didactic uses, assisting in personal, learning development and shaping new skills; ICT as a tool for teachers to support learning.

(iii) Supporting personal communication and interaction: ICT as a tool for alternative/augmentative communication to replace or supplement personal communication barriers; ICT as a tool to overcome social and/or geographical isolation.

(iv) Supporting access to educational administrative procedures: ICT as a tool to access administrative procedures in organizations; ICT as a tool to administer and improve services for learners with disabilities (Adopted from EADSNE and UNESCO IITE, 2013, p. 8).

\section{Overview}

\subsection{A Global Picture of PWD}

WHO develops a framework known as the International Classification of Functioning, Disability and Health (ICF) (Note 1) estimates that 15.6 percent of the world population over 18 years has some kinds of disabilities. Among these numbers, adults with very significant difficulties account for roughly $2.2 \%$ (92 million people in 2004) (WHO, 2011).

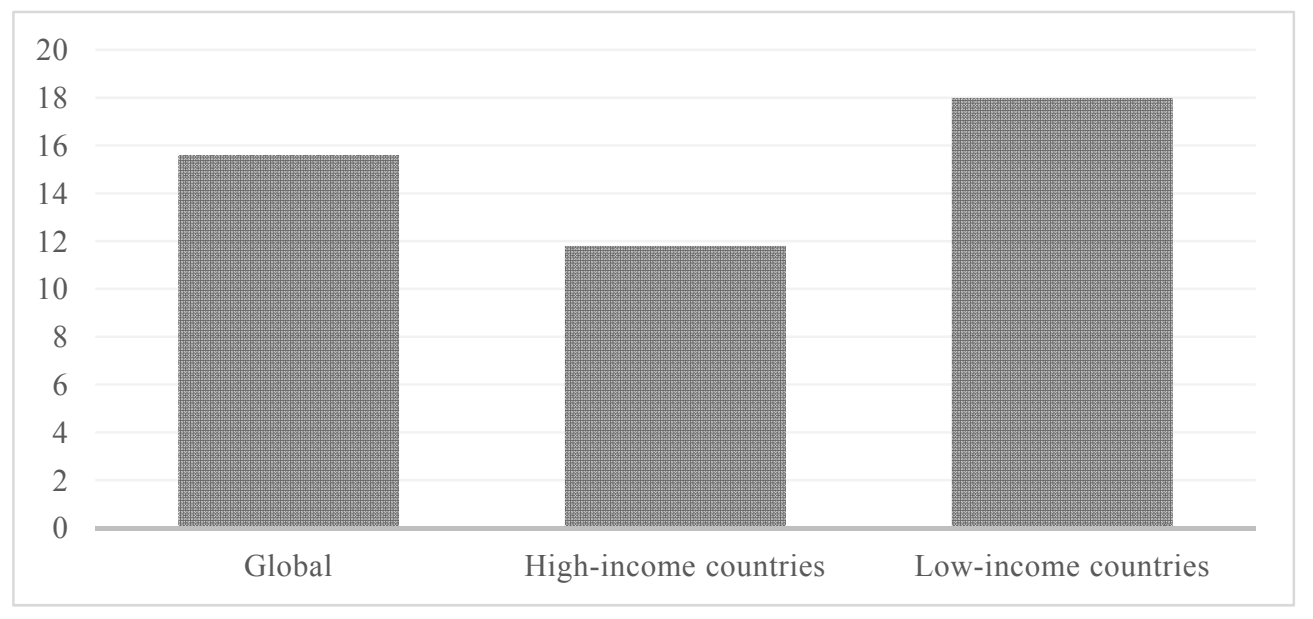

Figure 1 . Average disability prevalence rate in the adult population aged 18 years and over

Figure 1 shows that adults in low-income countries are more vulnerable to disabilities than in high-income countries (Note 2) (WHO, 2012).

This is especially an issue in the Asia-Pacific region, which is home of more than 60 percent of PWD in the world (UN Economic and Social Commission for Asia and the Pacific, 2014). Figure 2 shows the estimated number of PWD in some Asian countries (Asia-Pacific Development Center on Disability Country Profile, 2009). 


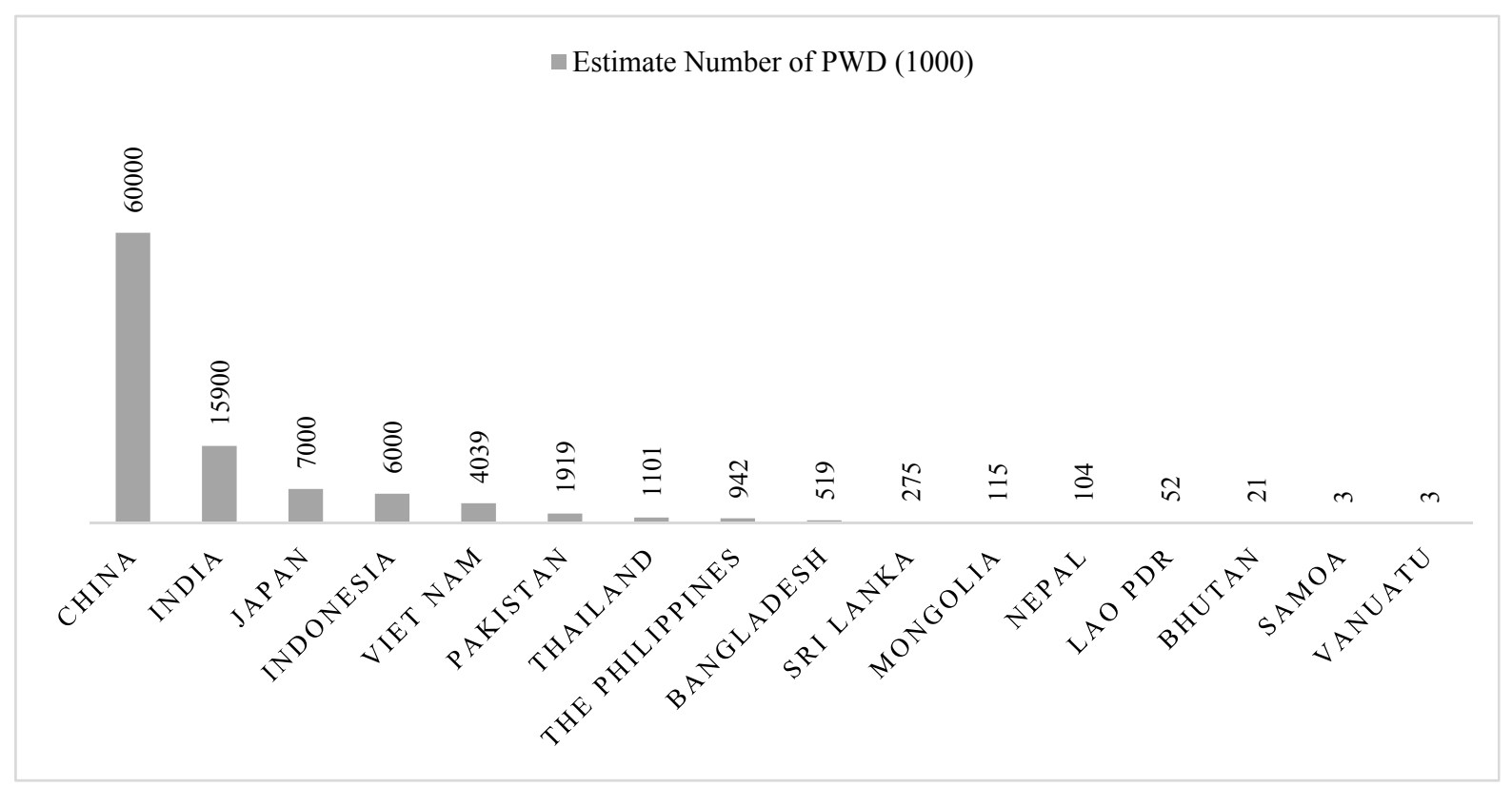

Figure 2. Estimate number of PWD in some Asian countries

Studies show that PWD are in general victims of severe conditions: unequal access to healthcare, higher rates of poverty, lower employment rates, lack of education, and related worse socioeconomic outcomes (Australian Institute of Health and Welfare, 2010; Gulley \& Altman, 2008; VanLeit et al., 2007; WHO, 2008b). Moreover, the need to improve the healthcare system and the creation of an enabling environment, ensuring a quality education for PWD, including equal access to all levels of education, is one of the essential tasks of the global community (UN CRPD, 2006).

\subsection{Education for People with Disabilities (Special Needs Education - SNE) (Note 3)}

The Global Burden of Disease by WHO estimates the number of children aged 0-14 years experiencing "moderate or severe disability" in 2004 at 93 million (5.1\%), with 13 million $(0.7 \%)$ children experiencing severe difficulties (WHO, 2008). The United Nations Children's Fund (UNICEF) estimated that there are 150 million children with disabilities (CWD) under age 18 in 2005 (UNICEF, 2008), these are among the world's most marginalized and excluded children (WHO, 2011).

In general, CWD have lower attendance and completion rates compared to children without disabilities, especially in low-income countries. The gap in primary school attendance rates between disabled and non-disabled children ranges from 10 percent in India to 60 percent in Indonesia, and for secondary education, from 15 percent in Cambodia to 58 percent in Indonesia (WHO, 2012). Higher income countries in Eastern Europe show the same tendency, the gap in enrolment rates between disabled children and non-disable children at the ages from 7 to 15 was about 25 to 30 percent in 2002 (Mete, 2008). The rates also vary in-between types of disability. For example, in Burkina Faso, only $10 \%$ of deaf 7- to 12-year olds were in school, while $40 \%$ of children with physical impairment attended in 2006 (UNESCO, 2011).

To address this issue, several models are being adopted around the world to provide education for PWD: special schools and institutions, integrated schools, and inclusive schools. Special schools or segregated education provide individualized education to a minority of children in urban areas, addressing specific needs of students (normally based on types of disabilities, most common models are schools for deaf/muted and schools for blind people). PWD in special schools do not attend classes with non-disabled students. Therefore, they have little to no social interaction with non-disable children in school settings. Integrated schools refer to the practice of educating PWD in classes with non-disabled students during specific periods, but PWD are educated in separate classes for the rest of the school day (Zittleman \& Miller, 2006). While these two models have been implemented widely and remain quite common in developing countries, the PWD in these models are exposed to the risk of social exclusion and discrimination.

Therefore, IE is an ambition and a goal, that all children regardless of ability or disability should be educated in 
mainstream classes in their district schools and receive education and support as required by their needs (UN CRPD, 2006). The Salamanca Statement on Principles, Policy, and Practice in Special Needs Education reassures that 'regular schools with inclusive orientation are the most effective means of combating discrimination, creating welcoming communities, building an inclusive society, and achieving education for all' (UNESCO, 1994).

\subsection{ICTs in Education}

There are various definitions of ICTs among the international community. While people often associate ICTs with the most updated, sophisticated, and rather expensive computer-based technologies, ICTs also includes many daily life technologies such as radios, televisions, or telephones. European Union (EU) defines ICTs as "a wide range of services, applications, and technologies, using various types of equipment and software, often running over telecom networks" (EU, 2001, p. 3).

The United Nations Educational, Scientific and Cultural Organization (UNESCO) uses the term ICTs to describe 'the tools and the processes to access, retrieve, store, organize, manipulate, produce, present, and exchange information by electronic and other automated means. These include hardware, software, and telecommunications in the forms of personal computers, scanners, digital cameras, phones, faxes, modems, CD and DVD players and recorders, digitized video, radio and TV programs, database programs, and multimedia programs (UNESCO Bangkok, 2003, p. 75).

The use of ICTs can be seen at every level of education, from early childhood care to higher education, as well as in different kinds of education including mass education, special education, inclusive education, and long-distance education. In learning and teaching activities, Resta and Patru (2010) find that the use of ICTs in instruction brings changes in teacher roles from "sages on the stage" to becoming "guides on the side" and student roles become more active and collaborative. ICTs with its strengths of accessibility and availability have the potential to bridge the knowledge gap, increase the quality of education and educational opportunities, and enable knowledge building (Asia Development Bank (ADB), 2009).

Hence, ICTs have proved themselves to be a powerful tool to support international education goals, among them is promoting Education for All and Education for Sustainable Development. UNESCO recognizes that ICTs "must be harnessed to support Education for All goals at an affordable cost. These technologies (ICTs) have great potential for knowledge dissemination, effective learning and the development of more efficient education services" (UNESCO, 2000). ICTs also contribute to education for sustainable development by increasing access to educational materials on sustainability and promoting the interaction and learning that emphasize not just knowledge, but choices, values, and actions (Paas, 2008).

\subsection{Types of ICTs in Inclusive Education}

ICTs for inclusion can be any technology to support learning activities in inclusive settings, including mainstream technology commercially available to anyone, such as laptops, tablets and peripherals, whiteboards and mobile phones (EADSNE and UNESCO IITE, 2013). However, it may also include three other common types. Accessible technologies (Note 4) are those designed to allow learners to use mainstream technology without hassles, while assistive technologies (Note 5) aim to specifically support learners with a certain disability or impairment (McKnight \& Davies, 2012). These two concepts nowadays are often intertwined, as ICT developers apply inclusive design approaches to accessible technologies with 'methods designed to make technologies or information accessible, therefore may be counted as assistive technology approaches, as the approach is assistive, even if the technology is not necessarily so' (McKnight \& Davies, 2012, p. 13). Another type of ICTs used in education for PWD is emerging technologies (Note 6), which are 'tools, concepts, innovations, and advancements utilized in diverse educational settings to serve varied education-related purposes' (Veletsianos, 2010).

\section{Methods}

A search in Scopus and ERIC was performed in May 2018 for the articles with the terms inclusive education and Asia and ICT (or similar terms, Note 7) in the titles and abstracts. The author then reviewed the results to identify relevant articles with the following criteria:

- Described a practice in an inclusive education setting in Asia

- Specified at least one kind of disability

- $\quad$ Specified the ICT tool(s) in the practice 


\section{The Use of ICTs in IE}

\subsection{ICTs to Support Personal Access to Information and Knowledge}

The Universal Declaration of Human Rights 1948 recognizes the freedom and ability to access and share information as a basic human right. UN CRPD reemphasizes this in Article 3 and 4: "provide accessible information to persons with disabilities" and the need to "the design, development, production and distribution of accessible information and communications technologies and systems" in Article 9. Article 24 states the right to education of PWD "without discrimination and based on equal opportunity", implies that accessing information is necessary for learning.

Nanasala Project in Sri Lanka refers to several models of telecenters established across Sri Lanka for provision of ICTs based services, including multi-ICTs service center in a rural area, mobile e-library, distance and e-learning centers, and ICTs kiosks at places affected by tsunamis. This project is not exclusively planned to serve PWD but to bring more ICTs accessibility to underprivileged people. However, the implementation of these models also reaches to PWD and proves to have positive results. Digital talking textbooks are distributed through the Nanasala network to people with visual impairments. Through their ICT-enabled network, the Nanasala operators can help families living with disabilities to apply for monthly support stipends issued by the National Secretariat for Persons with Disabilities. This project empowers PWD in Sri Lanka and supports them to overcome difficulties through the effective use of ICTs.

\subsection{ICTs to Support Learning and Teaching Situation}

ICTs used in supporting teaching and learning activities may be considered as the most common use in education. ICTs in most forms (e.g., video, print, computer, the Internet) can be easily used for presentation, demonstration and drill and practice, while networked computers and the Internet are best used for interaction and collaboration but still have not been exploited to the best potential (Dixit \& Gupta, 2010). The wide range of ICTs available and their strengths of customizability and adaptability make it extremely useful in SNE.

Wong and Cohen (2012) research the use of AT for students with visual impairments in a special school in Singapore by classroom observations and interview with 10 teachers/school leaders and 20 students with visual impairments. This study shows that there is a significant gap in knowledge and skills among teachers about the use of ATs. In addition, teachers have limited knowledge on which AT is available for each type of disabilities. The inconsistency can also be seen among students; some are familiar with ATs such as screen readers while some find it difficult to use keyboards (Wong \& Cohen, 2012).

Princess Maha Chakri Sirindhorn of Thailand has been known for her activeness in ICT projects since 1995. Her projects concentrate on include introducing computer technologies to school students, bringing in computer technologies for the disabled, and offering teachers access to and training in good-quality, commercially-available computer-assisted instruction programs (UNESCO Bangkok, 2004). In 1998, Srisangwan School joined the Princess's IT for Disabled Programme. Donated computers were set up were placed in the regular classrooms, 10 in each for grades 1 to 6 . This program is considered a great success, as the teachers are capable of using computer-assisted instruction programs to support their own teaching, special assistance is provided to students especially with difficulties in speaking, writing, and reading. Under the program, teachers are trained to assess the capabilities of disabled children to identify adequate assistance for them and to utilize IT tools in education for CWD effectively. Moreover, the program also works with physical therapists, speech therapists, special educationists, and computer instructors to support the school to create individual curricula to suit SEN of each student (UNESCO Bangkok, 2004).

\subsection{ICTs to Support Personal Communication and Interaction}

ICTs, when used in accordance with each child's SEN, would be effective to enhance their achievements and communication thereby promote independence and better interaction. In June 2012, Fujitsu developed a system that consists of four software called 'Fujitsu Education Solution K-12 SNE Kids Touch' to provide a better learning environment for children with SENs. This system is built on a touch-based surface, designed to develop the fundamental skills of children with SENs, such as intellectually handicapped children, physically disabled children, and developmentally disabled children (Ito, Nozawa, Miyairi, \& Takashi, 2015). This program has been piloted from October 2012 to February 2014 and shows exceptional strengths such as great accessibility, ability to import and export educational materials and record learning history and the easy user interface helps students quickly adapt to the system. Results also show that children are motivated to practice with the software, while teachers can monitor and keep track of the progress through the learning history. This model is now under 
modification according to feedback and suggestion during the pilot phase, promise to be a great supporting tool for education of children with SENs (Ito et al., 2015).

Other examples of ICTs supporting communication and interaction is the Eye-Based Pointing Device (Eye B-Pod) developed by students of the Bina Nusantara University in Indonesia, allows users to operate the computer by using their eyes. The other program, called Linux IGOS Voice Command is an an application in the Indonesian language Bahasa, allows users to operate their computers using voice commands with an application developed for the Linux platform (UNESCO, 2013).

\subsection{ICTs to Support Access to Educational and Administrative Procedures}

EADSNE and UNESCO IITE state that ICT as a tool for accessing administration "should not be seen as an end in itself-it should be seen as another opportunity for increasing educational opportunities and ultimately life chances" (2013, p. 71).

Jayakar, Liu, Madden and Park (2015) examined the Barrier-Free Access initiative coined by China Disabled Peoples Federation (CDPF) in 2005 and Web Content Accessibility Guidelines proposed by India Ministry of Communication and Information Technology in 2012. Both address the content access issues of PWD, aim to improve accessibility to government websites. CDPF planned to develop a cluster of websites for the public to access information on disabled person affairs, as a new strategic goal and urged the other government agencies to provide barrier-free service to the population with disabilities. Similarly, in India, all Indian government websites and Web applications were supposed to go under a modification to make them more usable, user-centric, and universally accessible (Jayakar et al., 2015).

However, there is a small number of government websites which were justified in both cases. The government's official websites failed the basic accessibility test. All of the Chinese government's websites examined with the Web Content Accessibility Guidelines 1.0 (WCAG) published by the World Wide Web Consortium (W3C) failed one or more of the W3C accessibility measures, leaving the difficulty of accessibility unsolved (Shi, 2006; 2007). In the case of India, a report by the Global Initiative for Inclusive ICTs (2012) found that only 3\% of websites were fully accessible, while the remaining $97 \%$ had at least one known accessibility problem.

Two initiatives said above started with good intentions but failed to implement. It is suggested that to promote accessibility, the government should work in partnership with other stakeholders (private sectors, civil society) and "catalyze specific programs and policies that would be beneficial to disability access and coordinate the activities of disparate interest groups" (Jayakar et al., 2015).

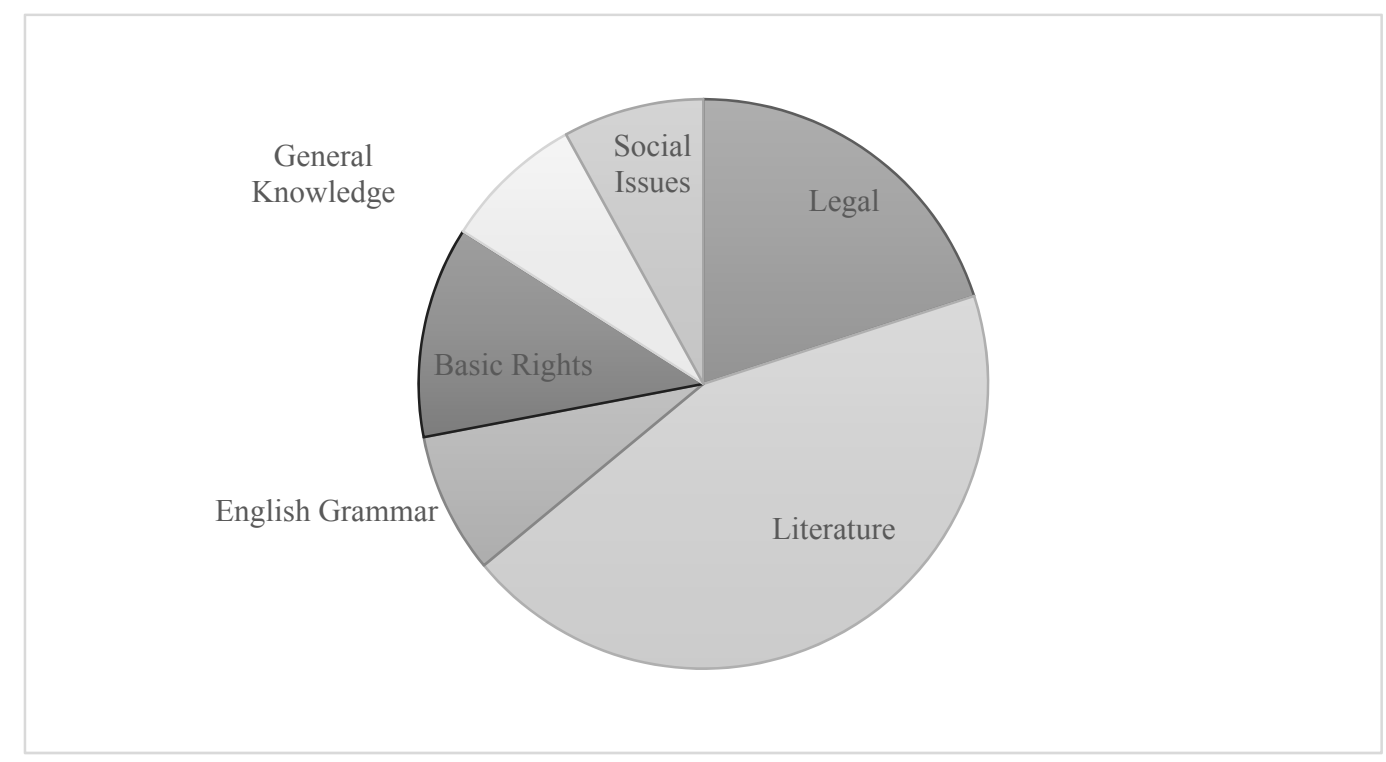

Figure 3. Type of information accessed by visual impaired students

Young Power in Social Action (YPSA) is a social development organization based in Chittagong District of Bangladesh, provides a program called Information, Communication, Technology and Resource Centers on Disabilities since 2005 to improve the accessibility of reading materials by print-disabled persons and provide 
livelihoods for the visually impaired through employment. YPSA partnered with Digital Accessible Information System (DAISY) Consortium, a not-for-profit organization promoting of advanced "audiobooks", also known as Digital Talking Books (DTBs) which consists of an audio file (convert from text and present aloud), a synchronization file (link text and audio) and a navigation control option (browse through the audio file with ease). This project attracts more than regular 1500 users in three sub-districts in Chittagong and distributes 3000 CDs of 50 titles in 2011.

Figure 3 shows that more than 40 percent of accessed information relates to social issues, legal, and basic rights (YPSA, 2011). Visual impaired students engaged in this project are reported to seek information from textbooks and newspapers in order to learn about policies and legal rights, job opportunities, and current affairs. A total of 75 percent of employees working at telecenters are visually impaired, allows better servicing of the visually impaired user groups as needs are understood at a personal level (Bhattacharjee, 2011)

DAISY for all helps PWD reach for more knowledge, especially information about legal and their rights. However, it faces the challenges of the sustainable fund, mismatched user demands, and a lack of DTB contents. Recommendations include improving monitoring and tracking system to tracking project progress and identifying gaps for provision of meaningful access to information, matching users with appropriate technologies and relevant information, strengthen partnership with other organizations for contents and distribution of DTBs (YPSA, 2011).

\section{Conclusion}

IE has grown from the belief that education is a basic human right and that it provides the foundation for a more just society. All learners have a right to education, regardless of their individual characteristics or difficulties (UNESCO, 2003). In this setting, ICTs is indeed a powerful tool to support education and inclusiveness of the people with disabilities.

The practices introduced above indeed contributed to the understanding of ICTs application in inclusive education However, it could be seen that most of the practices were/are conducted by non-governmental organizations with a limited budget and timeframe, which means the sustainability of those projects are questionable.

ICTs show a lot of positive impact on IE, but the use of ICTs is not an absolute solution for it, as stated that: "ICT in education for people with disabilities should not be seen as an end in itself-it should be seen as a means, or a tool for increasing effective access to and meaningful participation in educational opportunities" (EADSNE and UNESCO IITE, 2013, p. 86). Despite the shortcomings of ICTs application in inclusive education, ICTs have not been exploited fully to support IE. ICTs used in education in general and in IE require careful planning and close monitoring and tracking. EADSNE and UNESCO IITE recommend that government should take into consideration five key propositions identified within the 2006 UN CRPD in relation to the use of ICTs in education:

i. ICT should be considered as a key tool for promoting equity in educational opportunities, including promoting inclusive education.

ii. Access to appropriate ICTs should be considered an entitlement;

iii. Training of educational staff in the use of general and specialist ICT must be considered a priority area;

iv. The promotion of ICT research and development requires a multi stakeholder approach;

v. Data collection and monitoring in the use of ICT in inclusion should be considered an area requiring attention at all levels of educational provision (EADSNE and UNESCO IITE, 2013).

However, it is not possible for the government alone to implement the use of ICTs in inclusive education. ICTs application should not be a top-down policy but rather be a bottom-up which the special education needs are first identified and then resolved with appropriate ICTs application. Therefore, it requires efforts and resources from all stakeholders from the policymakers, private sectors, international organizations, school leaders, teachers, and especially people with disabilities themselves to make the best out of an ICTs-enabled inclusive education.

\section{References}

Asia-Pacific Development Center on Disability. (2018). Country Profile 2009. Retrieved July 10, 2018, from http://apcdfoundation.org/?q=content/country-profile

Asian Development Bank. (2009). Good practice in information and communication technology for education.

Australian Institute of Health and Welfare. (2010). Australia's health. Canberra. 
Bhattacharjee, V. (2011). Report on DAISY for ALL in Bangladesh. Young Power in Social Action. 2004-2008

Chamie, M. (1994). Can childhood disability be ascertained simply in surveys? Epidemiology, 273-275. https://doi.org/10.1097/00001648-199405000-00002

Dixit, J. B., \& Gupta, S. (2010). Excel with Information and Communications Technology. Laxmi Publications, Ltd.

European Agency for Development in Special Needs Education and UNESCO Institute for ICTs for Education. (2011). ICTs in Education for People with Disabilities: Review of innovative practice.

European Union. (2001). Information and Communication Technologies in Development: The role of ICTs in EC development policy. Brussels.

European Union. (2008). Press Release. 2868th Council meeting on Education, Youth and Culture. Brussels, $21-$ 22 May 2008.

Global Initiative for Inclusive ICTs. (2012). Accessibility of government websites in India. Retrieved June 26, 2018, from http://g3ict.com/download/p/fileId_931/productId_243

Gulley, S. P., \& Altman, B. M. (2008). Disability in two health care systems: access, quality, satisfaction, and physician contacts among working-age Canadians and Americans with disabilities. Disability and Health Journal, 1(4), 196-208. https://doi.org/10.1016/j.dhjo.2008.07.006

Harrigan, P. (2007). Sri Kanth walks tall in the IT world. Sunday Times Sri Lanka. Retrieved July 5, 2018, from http://www.sundaytimes.1k/071202/Plus/plus00011.html

Ito, T., Nozawa, A., Miyairi, M., \& Takaishi, K. (2015). Educational Support for Children with Special Needs: K-12 SNE Kids Touch. FUJITSU Sci. Tech. J, 51(1), 15-21.

Jayakar, K., Liu, C., Madden, G., \& Park, E. A. (2015). Promoting broadband and ICT access for disabled persons: Comparative analysis of initiatives in Asia-Pacific region. The Information Society, 31(4), 299-314. https://doi.org/10.1080/01972243.2015.1041664

Lindsay, G. (2007). Educational psychology and the effectiveness of inclusive education/mainstreaming. British Journal of Educational Phychology, 77(1), 1-24. https://doi.org/10.1348/000709906X156881

McKnight, L., \& Davies, C. (2012). Current perspectives on assistive learning technologies. 2012 review of research and challenges within the field. Kellogg College Centre for Research into Assistive Learning Technologies. https://doi.org/10.1108/17549451211235000

Mete, C. (ed.) (2008). Economic implications of chronic illness and disability in Eastern Europe and the former Soviet Union. Washington, World Bank. https://doi.org/10.1596/978-0-8213-7337-8

Nanasala Project. (2018). Digital Inclusion: Equality of Opportunity to the Visually Handicapped through ICT. Retrieved July 5, 2018, from http://nanasala.org/icta-handicapped.htm

Paas, L. (2008). How information and communications technologies can support education for sustainable development: Current uses and trends. Paper presented at the International Institute for Sustainable Development.

Pires, G., Nunes, U., \& Castelo-Branco, M. (2012). Evaluation of brain-computer interfaces in accessing computer and other devices by people with severe motor impairments. Procedia Computer Science, 14, 283-292. https://doi.org/10.1016/j.procs.2012.10.032

Resta, P. (2010). Teacher Development in an e-Learning Age. Open Education Research, 3.

Shi, Y. (2006). E-government web site accessibility in Australia and China: A longitudinal study. Social Science Computer Review, 24(3), 378-385. https://doi.org/10.1177/0894439305283707

Shi, Y. (2007). The accessibility of Chinese local government Web sites: An exploratory study. Government Information Quarterly, 24(2), 377-403. https://doi.org/10.1016/j.giq.2006.05.004

UN Economic and Social Commission for Asia and the Pacific. (2014). Statistical Yearbook for Asia and the Pacific 2014.

UNESCO. (1994). The Salamanca Statement and Framework for action on special needs education. Adopted by the World Conference on Special Needs Education; Access and Quality. Salamanca, Spain, 7-10 June 1994. UNESCO.

UNESCO. (2000). The Dakar Framework for Action: Education for All: Meeting Our Collective Commitments: 
Including Six Regional Frameworks for Action. UNESCO.

UNESCO. (2003). Open File on Inclusive Education. Support Materials for Managers and Administrators.

UNESCO. (2010). Reaching the marginalized EFA Global Monitoring Report 2010. Paris.

UNESCO. (2013). Global Report: Opening New Avenues for Empowerment ICTs to Access Information and Knowledge for Persons with Disabilities.

UNESCO Bangkok. (2003). Developing and Using Indicators of ICT Use in Education. Compiled by UNESCO Asia and Pacific Regional Bureau for Education, Bangkok, and Southeast Asian Ministers of Education Organization Regional Centre for Educational Innovation and Technology, Metro Manila, Philippines.

UNESCO Bangkok. (2004). Empowering all Thais with technologies. Retrieved July 4, 2018, from http://www.unescobkk.org/education/ict/online-resources/features/it-princess

UNESCO IITE. (2006). ICTs in Education for People with Special Needs-Specialized Training Course.

United Nations. (2006). Convention on the Rights of Persons with Disabilities. New York, United Nations General Assembly A/61/611. Retrieved December 6, 2006, from http://www.un.org/esa/socdev/enable/rights/convtexte.htm

United Nations Children's Fund, University of Wisconsin. (2008). Monitoring child disability in developing countries: results from the multiple indicator cluster surveys. New York.

Üstün, T. B., Kostanjsek, N., Chatterji, S., \& Rehm, J. (Eds.). (2010). Measuring health and disability: Manual for WHO disability assessment schedule WHODAS 2.0. World Health Organization.

VanLeit, B., Rithy, P., \& Channa, S. (2007). Secondary prevention of disabilities in the Cambodian Provinces of Siem Reap and Takeo: perceptions of and use of the health system to address health conditions associated with disability in children. Brussels, Handicap International.

Veletsianos, G. (Ed.). (2010). Emerging technologies in distance education. Edmonton, Canada: AU Press.

Wong, M. E., \& Cohen, L. (2012). Assistive technology use amongst students with visual impairments and their teachers: Barriers and challenges in special education. Research Brief; 12-005.

World Bank. (2004). Data and statistics: country groups. Washington.

World Health Organization. (2008). The global burden of disease: 2004 update. World Health Organization.

World Health Organization. (2008a). Closing the gap in a generation: Health equity through action on the social determinants of health. Geneva.

World Health Organization. (2011). World report on disability.

Young Power in Social Action. (2011). Center on Disabilities. Retrieved July 10, 2018, from http://www.ypsa.org/ircds.php

Young Power in Social Action. (2013). Accessible Reading Materials for the students with Visual and Print $\begin{array}{lllll}\text { Disabilities } & \text { Retrieved } & \text { July } & \text { 2018, } & \text { from }\end{array}$ https://ypsa.org/accessible-reading-materials-for-the-students-with-visual-and-print-disabilities/

Zittleman, K., \& Sadker, D. M. (2006). Teachers, Schools and Society: A Brief Introduction to Education with Bind-in Online Learning Center Card with free Student Reader CD-ROM (pp. 48, 49, 108, G-12). McGraw-Hill Humanities/Social Sciences/Languages.

\section{Notes}

Note 1. The International Classification of Functioning, Disability and Health, known more commonly as ICF, is a classification of health and health-related domains. As the functioning and disability of an individual occurs in a context. ICF also includes a list of environmental factors (Üstün, 2010).

Note 2. High-income countries are those with a 2004 gross national income (GNI) per capita of US\$10,066 or more in 2004, low-income and middle-income countries with a 2004 GNI less than US\$10,066 as estimated by the World Bank (World Bank, 2004).

Note 3. Special Needs Education is education for students with disabilities, in consideration of their individual educational needs, which aims at full development of their capabilities and at their independence and social participation. 
Note 4. For example, systems for people with motor disabilities to control a computer using neural or brain control (Pires et al., 2012).

Note 5. Specialist ICTs to support PWD are commonly referred to as assistive technologies, although there is no one single internationally accepted definition for this term (EADSNE and UNESCO IITE 2013). Hearing aids, speech recognition systems are two examples of assistive technologies.

Note 6. Massive Open Online Courses, mobile phones, robots, programmed objects are considered as examples of emerging technologies.

Note 7. Similar terms include ICTs, IT, information communication technology, information communication technologies, information technology, information technologies, technology, technologies.

\section{Copyrights}

Copyright for this article is retained by the author, with first publication rights granted to the journal.

This is an open-access article distributed under the terms and conditions of the Creative Commons Attribution license (http://creativecommons.org/licenses/by/4.0/). 